\title{
Comunicación
}

\section{ESTUDIO SEROLÓGICO DE FIEBRE AFTOSA Y BRUCELOSIS EN REBAÑOS MIXTOS DE CAMÉLIDOS Y OVINOS EN LA ECORREGIÓN DE SERRANÍA EN APOLOBAMBA, LA PAZ - BOLIVIA}

\author{
Foot And Mouth Disease And B rucellosis Serological Survey in Mixed \\ Herds of Camelids and Sheep in the Highlands of Apolobamba \\ Eco-Region, La Paz - B olivia
}
L. Fabián Beltrán-Saavedra S. ${ }^{1,2}$, Herminio Ticona Ch. ${ }^{1}$, Rodolfo Nallar G. ${ }^{1,3}$, José Luis Gonzáles R. ${ }^{4}$

\section{Resumen}

\begin{abstract}
El objetivo del presente estudio fue determinar niveles serológicos de anticuerpos contra fiebre aftosa y brucelosis en rebaños mixtos de alpacas y ovejas en cuatro comunidades de la ecorregión serranía en el Área Natural de Manejo Integrado Nacional Apolobamba, La Paz - Bolivia, colindante con Perú. Se colectaron 99 muestras de sangre de alpacas y 42 de ovinos de ambos sexos y edad diversa. Las muestras se procesaron mediante la prueba de inmunodifusión en gel agar para detectar anticuerpos VIA contra el virus de la fiebre aftosa y las pruebas de Aglutinación Rápida en Placa (prueba tamiz) y ELISA de competición (c-ELISA) (prueba confirmativa) para la detección de anticuerpos contra cepas lisas de Brucella sp. No se detectó anticuerpos contra fiebre aftosa o brucelosis.
\end{abstract}

Palabras clave : fiebre aftosa, Brucella sp, alpaca, camélido, ovinos, serología, Apolobamba

\section{AbStract}

The objective of the present study was to determine serological levels of antibodies against foot and mouth disease (FMD) and brucellosis in mixed herds of alpacas and sheep in four communities of the highlandecorregion of the Apolobamba Protected Area

\footnotetext{
${ }^{1}$ Programa Gran Paisaje Madidi-Tambopata, Wildlife Conservation Society, Calle Gabino Villanueva \#340 Calacoto, Casilla 3-35181 SM, La Paz, Bolivia

${ }^{2}$ E-mail: fabeltrans@yahoo.com

${ }^{3}$ Department of Veterinary Pathology, Western College of Veterinary Medicine, University of Saskatchewan, 52 Campus Drive, Saskatoon, SK S7N 5B4, Canada

${ }^{4}$ Servicio Nacional de Sanidad Agropecuaria e Inocuidad Alimentaria, La Paz, Bolivia
} 


\begin{abstract}
(National Integrated Management Natural Area - ANMIN), La Paz - Bolivia, bordering with Peru. Blood samples of 99 alpacas and 42 sheep of different sex and ages were collected. Plasma samples were tested for the detection of VIA antibodies against FMD virus using the agar gel immunodiffusion test (AGID-VIA) and for the detection of antibodies against smooth strains of Brucella spp. using a plate agglutination test as screening and a competitive ELISA (c-ELISA) as a confirmatory test. The results of the study showed no seropositive reactors for FMD or brucellosis.
\end{abstract}

Key words: foot and mouth disease, Brucella spp, alpaca, camelid, ovine, serology, Apolobamba

En el altiplano boliviano, la crianza de camélidos sudamericanos (CSA) se realiza generalmente en rebaños mixtos con ovinos. La producción de tipo familiar está concentrada en comunidades campesinas distribuidas en 20-25 millones de hectáreas. La producción ganadera se basa en pastoreo libre de praderas nativas. La producción de forrajes es escasa, de baja calidad nutricional, y se encuentra sujeta a heladas y sequías (Campero, 2005).

Las estimaciones de censos indican que existen cerca de 500 mil alpacas y casi nueve millones de ovinos en el altiplano boliviano (Campero H, 1990; Campero F, 2005). En el Área Natural de Manejo Integrado Nacional Apolobamba (ANMIN Apolobamba) se tiene 130 mil cabezas de ganado, donde el $86 \%$ son alpacas y el resto, en orden de importancia, son ovinos, bovinos y equinos (ARAUCARIA - SERNAP, 2004), distribuidas en las ecorregiones de pampa, serranía y cabecera de valle.

La fiebre aftosa es una enfermedad viral aguda muy contagiosa de los animales de pezuña hendida causada por un aftovirus con siete cepas conocidas en el mundo, y donde los serotipos $\mathrm{O}$, A y $\mathrm{C}$ han sido reportados en Bolivia (Kitching, 1999). Dada la importancia económica de esta enfermedad, el Programa Nacional de Erradicación de la Fiebre Aftosa (PRONEFA) entró en ejecución a partir del año 2000 (SENASAG, 2004), reduciéndose la incidencia de casos hasta el año 2003. No se detectaron focos de fiebre aftosa por casi cuatro años; sin embargo, en
2007 se presentaron focos con el tipo O en bovinos del departamento de Santa Cruz (OPS-PANAFTOSA, 2007), a $700 \mathrm{~km}$ de la región de Apolobamba. Asimismo, no se detectó la presencia de anticuerpos en estudios serológicos en llamas, alpacas y guanacos de Perú y Argentina, lo que sugeriría que no son huéspedes naturales (Parreño y Marcoppido, 2006); pese a que en 1970 se confirmó un caso de fiebre aftosa en alpacas luego de un brote de aftosa en bovinos de Perú (Moro y Guerrero, 1970).

La brucelosis es una enfermedad bacteriana causante de infecciones y abortos en los animales y se estima que se transmite anualmente a medio millón de humanos en el mundo. Las especies de Brucella comunes en el ganado son B. melitensis, $B$. abortus y B. ovis (Acha y Szyfres, 2003). Está ampliamente distribuida en Bolivia; y en la zona andina se reporta en bovinos y ovinos del departamento de La Paz (Condori y Huallata, 2007), pudiendo afectar a los CSA (Parreño y Marcoppido, 2006).

De acuerdo al Sistema Nacional de Vigilancia Epidemiológica del Servicio Nacional de Sanidad Agropecuaria e Inocuidad Alimentaria (SENASAG) de Bolivia, la fiebre aftosa y la brucelosis bovina se clasifican dentro de las enfermedades objeto de declaración obligatoria y notificación inmediata (SENASAG-ANEV, 2006).

Se han realizado estudios de brucelosis y fiebre aftosa en CSA y ovinos en las ecorregiones de pampa en 1997 y 2004 (Copa 
et al., 2003; Nallar et al., 2005) y en cabecera de valle (LF Beltrán, datos no publicados), no existiendo hasta el momento estudios de esta naturaleza en la ecoregión de sierra. Desde 2004, la Sociedad para la Conservación de Vida Silvestre (WCS por sus siglas en inglés) y su Programa Salud Integral de Ecosistemas (SIE) apoya en la vigilancia de enfermedades infecto-contagiosas de animales domésticos y fauna silvestre en nueve comunidades del ANMIN Apolobamba.

El objetivo de este estudio fue determinar, por vez primera, los perfiles serológicos de fiebre aftosa y brucelosis en rebaños mixtos de alpacas y ovinos del ANMIN Apolobamba. El estudio se realizó entre abril y mayo de 2007 en las comunidades de Antaquilla, Cañuhuma, Nube Pampa y Puyo Puyo, provincia Bautista Saavedra, frontera con Perú (ARAUCARIA-SERNAP, 2004).

El diseño de muestreo fue de detección de enfermedad. El cálculo del tamaño de muestra se hizo con el programa Win Episcope 2.0, asumiendo una prevalencia a nivel de hato del $10 \%$ en caso de existir fiebre aftosa o brucelosis (Thrusfield, 1990), un nivel de confianza del $95 \%$ y el total estimado de población mixta (camélidos y ovejas) en cada comunidad. Se estimó un tamaño mínimo de muestra por comunidad de 29 animales. Se colectó muestras de sangre de 99 alpacas de ambos sexos (50 hembras y 49 machos) y dos grupos de edad (38 juveniles y 61 adultos), y 42 ovinos de ambos sexos ( 22 hembras y 20 machos) y dos grupos de edad (11 juveniles y 31 adultos), los cuales no habían sido vacunados contra estas dos enfermedades.

El suero de cada muestra se conservó en nitrógeno líquido hasta su análisis serológico en el Laboratorio de Investigación y Diagnóstico Veterinario (LIDIVET) en Santa Cruz. Se empleó la prueba de inmunodifusión en gel agar para detectar anticuerpos VIA (IDGAVIA) de fiebre aftosa. Asimismo, para la detección de anticuerpos contra cepas lisas de Brucella sp. se aplicó un proceso seriado utilizando la Aglutinación Rápida en Placa con antígeno bufferado (ARP) como prueba tamiz, y las muestras positivas se trabajaron con la prueba competitiva de ELISA (c-ELISA) como prueba confirmatoria (98.9\% de especificidad en CSA, según Rojas et al., 2004).

Ninguna de las muestras presentó anticuerpos contra fiebre aftosa (Cuadro 1). Tampoco se detectó anticuerpos contra brucelosis en los ovinos, pero 12 muestras de alpacas dieron reacción positiva a Brucella sp. con ARP pero negativas con c-ELISA (Cuadro 1). En base a estos resultados, la máxima prevalencia esperada de fiebre aftosa o brucelosis, con un $95 \%$ de confianza, en cada una de las comunidades muestreadas se presenta en el Cuadro 2. Se estima que si una de estas enfermedades se encuentra en los rebaños evaluados, se tendría una prevalencia por debajo del $12 \%$.

El límite de detección de este estudio está dado por la prevalencia esperada de $10 \%$ utilizada en el diseño del trabajo, existiendo pocas probabilidades de detectar la enfermedad si la prevalencia en estos rebaños (si es que las enfermedades están realmente presentes) es menor a la prevalencia esperada. En caso de enfermedades crónicas como la brucelosis, se espera una prevalencia inferior al $10 \%$ a nivel de hato, y este estudio no cuenta con la suficiente sensibilidad para detectar animales infectados, si es que existieran en el rebaño. Estos resultados, aunados a los observados en otras ecorregiones del ANMIN Apolobamba (Nallar et al., 2005; LF Beltrán, datos no publicados) indicarían la posible ausencia de brucelosis (cepas lisas) en los rebaños de CSA y ovinos.

Por otro lado, la fiebre aftosa es una enfermedad altamente contagiosa, y se espera que circule en rebaños de CSA y ovinos no vacunados (asumiendo que la transmisión por contacto es similar a poblaciones bovinas) en prevalencias superiores al 10\% (Bronsvoort et al., 2006; Goris et al., 2007). La ausencia de reactores en este estudio podría ser un indicador de la posible ausencia de la infección 
Cuadro1. Resultados del monitoreo serológico de fiebre aftosa y brucelosis en rebaños mixtos de cuatro comunidades de la ecorregión serranía del ANMIN Apolobamba

\begin{tabular}{|c|c|c|c|c|c|c|}
\hline \multirow{3}{*}{ Comunidad } & \multirow{2}{*}{\multicolumn{2}{|c|}{$\begin{array}{l}\text { Fiebre aftosa } \\
\left(\text { IDGA VIA }^{1}\right)\end{array}$}} & \multicolumn{4}{|c|}{ Brucelosis } \\
\hline & & & \multicolumn{2}{|c|}{$\left(\mathrm{ARP}^{2}\right)$} & \multicolumn{2}{|c|}{$\left(\mathrm{c}-\mathrm{ELISA}^{3}\right)$} \\
\hline & Alpacas & Ovinos & Alpacas & Ovinos & Alpacas & Ovinos \\
\hline Antaquilla & $0 / 22$ & $0 / 18$ & $3 / 22$ & $0 / 18$ & $0 / 3$ & - \\
\hline Cañuhuma & $0 / 33$ & $0 / 10$ & $4 / 33$ & $0 / 10$ & $0 / 4$ & - \\
\hline Nube Pampa & $0 / 20$ & $0 / 8$ & $1 / 20$ & $0 / 8$ & $0 / 1$ & - \\
\hline Puyo Puyo & $0 / 24$ & $0 / 6$ & $4 / 24$ & $0 / 6$ & $0 / 4$ & - \\
\hline Total & $0 / 99$ & $0 / 42$ & $12 / 99$ & $0 / 42$ & $0 / 12$ & - \\
\hline
\end{tabular}

Cuadro 2. Máxima prevalencia esperada de fiebre aftosa o brucelosis en rebaños mixtos de cuatro comunidades de la ecorregión serranía del ANMIN Apolobamba

\begin{tabular}{|c|c|c|c|}
\hline Comunidad & $\begin{array}{c}\text { Población } \\
\text { aproximada en } \\
\text { rebaños mixtos }\end{array}$ & $\begin{array}{l}\text { N. }{ }^{\circ} \text { de muestras } \\
\text { analizadas }\end{array}$ & 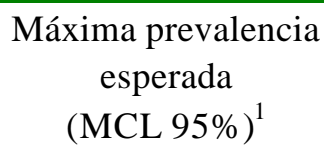 \\
\hline Antaquilla & 600 & 40 & 8.5 \\
\hline Cañuhuma & 2500 & 43 & 8.15 \\
\hline Nube Pampa & 1670 & 28 & 12.24 \\
\hline Puyo Puyo & 2240 & 30 & 11.5 \\
\hline
\end{tabular}

${ }^{1}$ Máximo límite de confianza de la prevalencia al 95\%

en la zona. Sin embargo, estos resultados deben ser considerados con cuidado, tomando en cuenta los límites de sensibilidad de la prueba IDGA-VIA.

En la región estudiada, existe un importante movimiento de ganado y venta de subproductos entre Bolivia y Perú, convirtiendo a la zona en un punto prioritario para la vigilancia epidemiológica. Hasta la fecha existe poco control sanitario a nivel de estas fronteras. Este estudio reporta datos iniciales que pueden servir de base para el diseño de monitoreos que sean parte de las actividades de vigilancia necesaria en la zona.

\section{Agradecimiento}

Los autores agradecen al Área Natural de Manejo Integrado Nacional Apolobamba. Programa Gran Paisaje Madidi - Tambopata, Sociedad para la Conservación de Vida Silvestre - Salud Integral de Ecosistemas, USAID, y Gordon and Betty Moore Foundation por las facilidades prestadas para la realización del estudio. Asimismo, a las comunidades de Antaquilla, Cañuhuma, Nube Pampa y Puyo Puyo que permitieron utilizar sus alpacas y ovinos. 


\section{Literatura Citada}

1. Acha N, Szyfres B. 2003. Zoonosis y enfermedades transmisibles comunes al hombre y los animales: Vol I. $3^{\mathrm{a}}$ ed. Washington DC: Publicaciones Científicas y Técnicas No 580. OPS-OMS. 398 p.

2. ARAUCARIA-SERNAP. 2004. Manejo sostenible de la vicuña en Apolobamba. La Paz, Bolivia: Agencia Española de Cooperación Internacional. $148 \mathrm{p}$.

3. Bronsvoort BM, Toft N, Bergman IE, Sorensen J, Anderson J, Malirat V, Tanya VN, Morgan K. 2006. Evaluation of three 3 ABC ELISAs for foot and mouth disease non-structural antibodies using latent class analysis. BMC Vet Res 2:30. [Internet]. Available in: http:// www.biomedcentral.com/1746-6148/2/ 30.

4. Campero F. 2005. Situación actual de los camélidos sudamericanos en Bolivia. Roma: FAO. 55 p.

5. Campero H. 1990. Evaluación coprológica e identificación de endoparásitos en llamas (Lama glama) y alpacas (Lama pacos) y su control con plantas medicinales nativas. Tesis de grado. Cochabamba, Bolivia: Univ. Mayor de San Simón. 156 p.

6. Condori R, Huallata C. 2007. Diagnóstico y prevalencia de la brucelosis en ovinos y bovinos en los departamentos de La Paz y Oruro. En: Congreso Internacional de Veterinaria y Zootecnia. Tarija, Bolivia.

7. Copa S, Suxo M, Vino N. 2003. Incidencia de brucelosis en alpacas en las comunidades del Cantón Ulla Ulla del departamento de La Paz. En: III Congreso Mundial de Camélidos. Vol. II. Potosí, Bolivia.

8. Goris N, Praet N, Sammin D, Yadin $H$, Paton D, Brocchi E, Berkvens D, De Clercq K. 2007. Foot-and-mouth disease non-structural protein serology in cattle: Use of a Bayesian framework to estimate diagnostic sensitivity and specificity of six ELISA tests and true prevalence in the field. Vaccine 25: 71777196.

9. Kitching RP. 1999. Foot and mouth disease: current world situation. Vaccine 17: 1772-1774.

10. Moro M, Guerrero G. 1971. La alpaca: enfermedades infecciosas y parasitarias: Centro de Investigación Tropical y de Altura. Lima Perú. 63 p.

11. Nallar R, Morales A, Gonzales JL, Gómez H, Casilla A. 2005. Evaluación de la salud de vicuñas (Vicugna vicugna) en estado silvestre en el Área Natural de Manejo Integrado Apolobamba, La Paz - Bolivia. En: I Congreso Nacional de Mastozoología en Bolivia. Cochabamba, Bolivia.

12. OPS-PANAFTOSA. 2007. Resultados de la caracterización molecular del virus de fiebre aftosa del foco del municipio de Cuatro Cañadas, Depto. Santa Cruz, Bolivia. Brasil: Centro Panamericano de Fiebre Aftosa. Informe de foco epidemiológico. $3 \mathrm{p}$.

13. Parreño V, Marcoppido G. 2006. Estudio de la sanidad en camélidos: Avances a partir de la obtención de muestras de camélidos silvestres. En: Vilá B, ed. Investigación, conservación y manejo de vicuñas. Argentina: Proyecto MACS Universidad de Luján. p 147-164.

14. Rojas X, Muñoz S, Otto B, Pérez B, Nielsen K. 2004. Utilización de los test de fluorecencia polarizada (FP) y ELISA de competencia (c-ELISA) en el diagnóstico de brucelosis de camélidos. Arch Med Vet 36(1): 59-64.

15. SENASAG-ANEV. 2006. Manual del sistema nacional de vigilancia epidemiológica. Bolivia: Servicio Nacional de Sanidad Agropecuaria e Inocuidad Alimentaria. $62 \mathrm{p}$.

16. SENASAG. 2004. Bolivia: Ministerio de desarrollo rural, agropecuario y de medio ambiente. [Internet], [01 noviembre 2008]. Disponible en: http:// w w w . s e n a s a g. g o v. bo/ index.php?option=content\&task=view\&id=2.

17. Thrusfield M. 1990. Epidemiología ve terinaria. Zaragoza, España: Acribia. 339 p. 